\title{
A Multidimensional Commitment Model of Volitional Systems Adoption and Usage Behavior
}

\author{
YOGESH MALHOTRA AND DENNIS GALLETTA
}

Yogesh MALHOTRA earned his Ph.D. in Business Administration from the University of Pittsburgh's Katz Graduate School of Business in 1998. Before joining the faculty of Syracuse University Whitman School of Management teaching MIS and Supply Chain Management, he taught as invited faculty for the Northwestern University's Kellogg School of Management and the Carnegie Mellon University's Graduate School of Industrial Administration. His research interests include adoption and utilization of information and communication technologies, knowledge management, and technology and innovation management. Citation analyses studies by IBM and University of Minnesota list him among the world's most-cited authors on knowledge management and the world's seminal contributors in knowledge management. His research is published in two research monographs and more than 50 journal articles, book and encyclopedia chapters, conference proceedings, and reprints. He has served or serves on the editorial, advisory, and review boards of several leading research journals and received R\&D grants from the United Nations, Intel Corporation, and SAP University Alliance, among others. His consulting engagements on corporate strategy, national policy, and world development include some of the world's largest governments and corporations and the United Nations. His research, analyses, interviews, and technology ventures have been featured in Business Week, Fortune, Wall Street Journal, Forbes, Fast Company, Business 2.0, Chief Executive, CIO Magazine, CIO Insight, Computerworld, InformationWeek, and other worldwide media and publications.

DENNIS Galletta is an AIS Fellow and Professor of MIS at the Fox School of Business, Temple University, and Professor of Business Administration at the Katz School, University of Pittsburgh. He obtained his Ph.D. in MIS from the University of Minnesota. His current research interests cover end-user behavior, attitudes, and performance. His articles have appeared in journals such as Management Science, Information Systems Research, Journal of Management Information Systems, Communications of the ACM, Decision Sciences, Data Base, Information and Management, and Journal of AIS. He has served on several editorial boards, including MIS Quarterly, Data Base, and Information Systems and e-Business Management. His research studies have also been featured in outlets such as Business Week, Wall Street Journal, Computerworld, and CNN. He is currently editing a two-volume collection of research on HumanComputer Interaction in the MIS field for Vladimir Zwass's series Advances in MIS. He taught undergraduate information systems courses during the fall 1999 Semester at Sea Voyage, served as the ICIS Treasurer from 1994 to 1998, was a member of the AIS Council representing the Americas in 1996 and 1997, chaired the first Americas Conference for AIS (AMCIS), was program cochair for both ICIS (2005) and AMCIS (2003), and is Editor-in-Chief of ISWorld.

\footnotetext{
Journal of Management Information Systems / Summer 2005, Vol. 22, No. 1, pp. 117-151.

(c) 2005 M.E. Sharpe, Inc

$0742-1222$ / $2005 \$ 9.50+0.00$.
} 
ABSTRACT: In recent years, several organizations have implemented nonmandatory information and communication systems that escape the conventional behavioral logic of understanding acceptance and usage from a normative perspective of compliance with the beliefs of others. Because voluntary systems require users' volitional behavior, researchers have traced recent implementation failures to a lack of user commitment. However, gaps in our understanding of volitional usage behavior and user commitment have made it difficult to advance theory, research, and practice on this issue. To validate a proposed research model, cross-sectional, between-subjects, and within-subjects field data were collected from 714 users at the time of initial adoption and after six months of extended use. The model explained between 44.1 percent and 58.5 percent of the variance in adoption and usage behavior based upon direct effects of user commitment. Findings suggest that user commitment plays a critical role in the volitional acceptance and usage of such systems. Affective commitment-that is, internalization and identification based upon personal norms-exhibits a sustained positive influence on usage behavior. In contrast, continuance commitment-that is, compliance based upon social norms-shows a sustained negative influence from initial adoption to extended use. Theory development based upon Kelman's social influence framework offers new empirical insights about system users' commitment and how it affects volitional usage behavior.

KEY WORDS AND PHRASES: affective processes, cognitive processes, information systems acceptance and use, multidimensional commitment model, personal norms, psychological attachment, social influence theory, social norms, systems implementation, user commitment, volitional usage behavior.

ORGANIZATIONAL INFORMATION SYSTEMS (IS) were once primarily used to enforce managerial compliance for the execution of specific work activities. Accordingly, prior IS acceptance and usage research focused mainly on understanding systems usage behavior from the perspective of social normative compliance [40, 70, 71]. This perspective considers the principal challenge as motivating the system user to "comply" and "conform" to the beliefs of salient others. Accordingly, prior research paid sparse attention to how the system user's own beliefs influence commitment to adopt and use technology.

However, in recent years, many organizations began implementing new types of information and communication systems that involve volitional communication, collaboration, and coordination activities [2, 29, 63]. Both practitioners and researchers recognize that managerial coercion to achieve compliance is often neither feasible nor economical. Several surveys and case studies have found that systems intended to support those self-determined knowledge activities, such as use, sharing, creation, and renewal, often fail because of the lack of user commitment [2, 29, 39, 42, 43, 63].

For instance, potential users of the $\$ 6.9$ billion Navy/Marine Corps Intranet (N/MCI) project were "fighting N/MCI so long, it (became) a passion" for them [73, p. 16]. Their lack of commitment prolonged the expected project duration eightfold: it took two years to do what could have been accomplished in 90 days. Similarly, a scientist 
at Pillsbury, who developed a simple system for "knowledge sharing," seeded it with questions, and sent out e-mail invitations to potential participants. After six months of waiting, however, not even a single user had posted any messages [11].

The same distinctive characteristics that make such systems dependent upon volitional usage also limit the effectiveness of managerial mandates for enforcing their use through social normative compliance. Rather, such systems require proactive commitment of users to share, create, and renew knowledge through the activities of communication, collaboration, and coordination. Recognizing this critical need, many have called for a better understanding of volitional systems usage behavior $[2,5,24$, $29,41,42,43,65,79]$. In response, the current study develops the first known theoretical, psychometric, and empirical understanding of the volitional nature of system user commitment and how it affects volitional system usage behavior.

The proposed theoretical constructs and the research model were examined in a field setting, and cross-sectional, between-subjects, and within-subjects data were collected from 714 system users at the time of initial adoption and after six months of extended use. Theory development based upon Kelman's [34, 35, 36] social influence theory offers new empirical insights about system users' commitment and how it affects volitional usage behavior. Theoretical and psychometric validity of the proposed model is augmented by the use of precise constructs and measures substantially supported by four decades of sociopsychological behavioral research on the psychology of commitment $[34,35,36]$.

Besides developing a theoretically precise and psychometrically consistent conceptualization of the system user commitment construct, other key objectives of this research include developing theoretical, psychometric, and empirical understanding of (1) how user commitment affects volitional systems usage behavior; (2) how different types of commitment have differential influence on volitional systems usage behavior; and (3) how different types and levels of commitment evolve from initial adoption to extended use of a system.

\section{Theory Development}

THE VOLITIONAL NATURE OF SELF-DETERMINED systems usage activities of communication, collaboration, and coordination makes them critically dependent upon user commitment. It is important that users be active and engaged not only for using information but also for sharing, creating, and renewing it. "Knowledge repositories" and "communities of practice," for example, often rely upon users to both make effective use of, and contribute proactively to, their sustenance. However, such proactive engagement and volitional contributions often depend upon users' personal norms and values [20].

From the normative social compliance perspective, managerial attempts to enforce usage through "quotas" (such as the number of messages that "must" be read or posted) are uneconomical to enforce, and even when enforced, may, at best, yield suboptimal contributions. As evident from the earlier vignettes, stiff user resistance and implementation failure are likely outcomes. Hence, it is critical to distinguish between 
different levels and types of commitment, as less managerial control might actually be necessary for achieving more proactive usage.

Kelman's social influence theory provides a well-established basis for distinguishing a variety of types and levels of commitment. This theory has motivated substantial cumulative research on commitment in the context of organizational work behaviors. Unfortunately, prior IS research has taken a very limited perspective of Kelman's theory by interpreting it from a cognitive perspective with primary focus on social normative compliance $[19,40,70]$. Known psychometric and theoretical limitations of subjective norms (observed by [17, 19, 40,74]) limit its reliability as a proxy for user commitment despite the popularity of this practice in prior IS research. Also, as shown in Table 1, the use of divergent social influence theories has resulted in interpretations that are inconsistent with four decades of cumulative research on Kelman's processes of commitment [34, 35].

The primacy of others' beliefs (rather than self-beliefs emphasized by Kelman) in influencing system users' behavior is evident in prior interpretations [40,70] primarily focused on social normative compliance. Also, confusion can result from having to choose from an abundance of divergent theories (e.g., [8, 21, 26, 27, 30, 37, 48, 55, $56,60,62,74])$ for interpreting Kelman's processes of commitment. Inconsistent theoretical interpretations also seem to underlie the "equivocal findings" of empirical research on prior research on social influence [40].

Prior studies have attempted to understand system users' motivation to comply to determine how their compliance to subjective norms affects their systems usage behavior $[40,70]$. The diverse social influence theories proposed in those studies perhaps provide multiple lenses for extensive analysis of specific constructs necessary to reconcile the equivocal empirical findings reported in prior IS literature. Our focus on user commitment was motivated by the lack of systematic attention given to this construct despite its critical influence on systems usage behavior. Our study was also motivated by a careful review of the substantial cumulative research on commitment centered on Kelman's social influence processes.

\section{Kelman's Social Influence Theory}

Diverse interpretations of commitment in management research $[9,49,64,75]$ refer to antecedents and consequences of behavior as well as to the process and state of attachment to specific behaviors. Kelman's theory of social influences [34, 35, 36], however, argues that psychological attachment (to specific behaviors) is the construct of interest [52]. Consistent with the cumulative research on Kelman's theory of social influences that motivated the current research, we define user commitment as the users' psychological attachment to system use.

In contrast to prior IS research on social influence and system user commitment, Kelman's theory argues for understanding such commitment from the standpoint of "the committed" [58]. Hence, the proposed model attempts to understand behavioral commitment to systems usage "through the eyes of the users" [61]. It underscores how users proactively follow their own beliefs-rather than simply complying with 
Table 1. Prior Conceptualizations of Internalization, Identification, and Compliance with Purely Cognitive Focus on Social Norms

\begin{tabular}{|c|c|}
\hline Venkatesh and Davis [70] & Lewis et al. [40] \\
\hline $\begin{array}{l}\text { Internalization: The "influence to } \\
\text { accept information from others as } \\
\text { evidence about reality" and "if a } \\
\text { superior or co-worker suggests that a } \\
\text { particular system might be useful, a } \\
\text { person may come to believe that it is } \\
\text { actually useful" [70, p. 189] integrating } \\
\text { literatures from diverse social influence } \\
\text { theories by Deutsch and Gerard [21], } \\
\text { French and Raven [26], Salancik and } \\
\text { Pfeffer [62], Fulk et al. [27], and Rice } \\
\text { and Aydin [60]. }\end{array}$ & $\begin{array}{l}\text { Internalization: "Via internalization, the } \\
\text { individual incorporates the opinion of an } \\
\text { important referent as part of her own belief } \\
\text { structure: in essence, the referent's beliefs } \\
\text { become one's own" [40, pp. 657-678]. }\end{array}$ \\
\hline $\begin{array}{l}\text { Identification: The "social normative } \\
\text { influences to maintain a favorable } \\
\text { image within a reference group" [70, } \\
\text { p. 189] based upon social influence } \\
\text { concepts proposed by Blau [8], } \\
\text { French and Raven [26], Kiesler and } \\
\text { Kiesler [37], Moore and Benbasat [48], } \\
\text { and Pfeffer [55, 56], }\end{array}$ & $\begin{array}{l}\text { Identification: "Via identification, the } \\
\text { individual seeks to believe and act in a } \\
\text { manner similar to those possessing referent } \\
\text { power. Therefore, compelling messages } \\
\text { received from important others are likely to } \\
\text { influence one's cognition about the expected } \\
\text { outcomes of technology use" [40, pp. } 657- \\
678] \text {. }\end{array}$ \\
\hline $\begin{array}{l}\text { Compliance: The "direct compliance } \\
\text { effect of subjective norm on intention } \\
\text { theorized to operate whenever an } \\
\text { individual perceives that a social } \\
\text { actor wants him or her to perform a } \\
\text { specific behavior, and the social } \\
\text { actor has the ability to reward the } \\
\text { behavior or punish nonbehavior" [70, } \\
\text { p. 188] based on Hartwick and Barki } \\
\text { [30], French and Raven [26], and } \\
\text { Warshaw [74]. }\end{array}$ & $\begin{array}{l}\text { Compliance: Not conceptualized or } \\
\text { distinguished from Internalization or } \\
\text { Identification, but implicit in above } \\
\text { conceptualizations of internalization and } \\
\text { identification. However, they primarily focus } \\
\text { on system users' "motivation to comply" to } \\
\text { others' beliefs: "Doubtless, the potency of } \\
\text { the influence will vary, depending on the } \\
\text { significance an individual assigns to } \\
\text { internalizing another's beliefs or identifying } \\
\text { with them" [40, pp. 676-677]. }\end{array}$ \\
\hline
\end{tabular}

beliefs of others. Unlike the social normative compliance assumed in prior research $[40,70]$, three levels of psychological attachment result from proactive choices made by users in conformance with their own beliefs.

Internalization, identification, and compliance represent differential commitments $[6,40,59]$ resulting from a desire to satisfy different personal goals. Internalization occurs when system users adopt behavior because of its content that they find congruent with their own personal values. Identification occurs when system users adopt attitudes and behaviors to achieve a satisfying, self-defining relationship with another person or group. In identification, the content of the behavior is irrelevant to the system user who is motivated simply by the salience of the relationship. Finally, compliance occurs when the user adopts particular behaviors to obtain rewards or avoid 
punishments. In this case, induced behavior is based neither on content of the behavior nor on the salience of relationships.

In stark contrast to prior research that focused on system users' motivation to comply $[40,70]$, our conceptualization views the system user as more volitional and selfdetermining in choosing to comply or not. Interestingly, Kelman interpreted the apparent "power" of social influences and referents as "the extent to which the influencing agent is perceived as instrumental to the achievement of the [individual's] goal" [34, p. 54]. In this view, the user adopts the specific behavior, or commits to it, to fulfill his or her own instrumental goals.

By distinguishing between different types of commitment underlying usage behavior, one can "make different predictions about the manifestations and consequences of the new attitudes; about their durability; about the number of different attitudinal areas that will be affected by them; and about the ways in which they will be translated into action" [34, p. 52]. The proposed model therefore provides a validated theoretical and empirical foundation for relating the three types of commitment processes to specific measurable changes in user attitudes and behaviors. It also provides a means for predicting manifestations and consequences of adoption of system usage behaviors, their transient or lasting nature, and how they link to specific actions. It holds the potential of relating successful systems use to specific individual and organizational outcomes based upon such actions.

\section{Identification, Internalization, and Compliance}

Kelman [34] argued that it is not enough to know that there has been a measurable change in an individual's behavior and attitude, but also to know whether the change is superficial and transient or is a lasting change, manifested in systems usage behavior and integrated in the person's values. While compliance denotes public conformity without private acceptance of the behavior, identification and internalization indicate public conformity that is accompanied by increasing levels of private acceptance. Meaningful predictions of systems usage behavior thus depend upon knowing the nature and depth of change in those behaviors that are reflected in subsequent actions. Recognizing different levels of users' psychological attachment to specific behaviors provides the basis for developing specific hypotheses about the conditions of behavior change. Empirical analysis can then help us understand the conditions that are conducive to lasting changes in behavior and how such changes are affected by personal norms and social norms.

Kelman [34] argued that changes in behaviors produced by social influence may occur at different "levels," observing that differences in the nature or level of such changes correspond to differences in the process whereby the individual accepts influence. Based upon an observation that "the underlying processes in which the individual engages when he adopts induced behavior may be different, even though the resulting overt behavior may appear the same" [54, p. 53], Kelman attributed differential commitment of the individual to the three processes (identification, internalization, and compliance). 
The three processes of commitment represent qualitatively different ways of accepting influence that determine the likely durability of the adopted systems usage behavior. Behavior adopted through internalization is integrated with the user's own values and becomes a part of his or her personal norms. Behavior adopted through identification is performed only under conditions of salience of the individual's relationship to the influencing agent. In contrast, behavior based upon compliance will be performed by the user only under conditions of surveillance by the influencing agent. Thus personal norms and values based on psychological attachment to the new behavior influence system usage.

\section{Personal Norms and Social Norms}

Researchers [19, 32, 40, 45, 68, 70, 74] have recommended advancing beyond a purely cognitive focus on subjective norms. Simultaneously, management researchers (e.g., $[1,7]$ ) have argued that personal norms and social norms need to be used together for understanding individual commitment based upon social influence. This study follows on the above recommendations by depicting the role of both personal and social norms in shaping affective and continuance commitments.

The contrast between personal and social norms is critical for recognizing the centrality of system user's own beliefs versus how those beliefs "conform" to others' beliefs. Social norms operate through an individual's beliefs as to whether important others think he or she should conduct a given action (i.e., normative belief). The individual's "motivation to comply" to others' cognitive representations, manifested in induced behavior, is relevant to subjective norms but is of less relevance to personal norms. Compared with volitional behavior based on internalization or identification, behavior driven by motivation to comply is not volitional [25, 33, 34]. Therefore, compliance involves a reconciliation of induced behavior through a "calculative" process of assessing the costs and benefits of "complying."

In contrast to subjective norms, personal norms are embedded in the individual's self-concept based upon one's own value systems and beliefs. Understanding of personal norms requires recognition of the values that intrinsically guide behavior and determine if the induced behavior is accepted or rejected. Adoption of new behaviors based upon personal identification with the espoused values may represent the first step toward internalization of such behaviors. Such internalized social norms are incorporated into an individual's self-concept and thus form his or her personal norms [25]. Personal norms are measured in terms of a scale anchored by "I should" and "I should not" in contrast to subjective norms that are measured by a scale anchored by "most people who are important to me think I should" and "most people who are important to me think I should not" [33].

\section{Affective and Continuance Conceptualizations of Commitment}

Recognizing that system usage behavior is a function of users' affect and cognition, IS researchers $[32,45,68]$ have recommended advancing the understanding of affective 
processes. Their counsel finds support in increasing emphasis of behavioral research on affective conceptualization of commitment underlying employees' behavioral intentions and attitudes [1, 3, 14, 47, 57]. Simultaneously, some behavioral researchers $[1,7,52,53]$ have proposed how to develop "multidimensional" understanding of commitment by integrating the missing affective dimension. Many have also suggested the theoretical relevance of system users' affective processes to success of system use $[31,50]$.

Approaching commitment from the perspective of psychological attachment, some may commit to use the system because of factors other than values, goals, and identification. For example, for some users, costs for not using the system may be too high. Based upon Meyer and Allen's [46] research on commitment, psychological attachment has two different dimensions: (1) an affective conceptualization of commitment, which refers to commitment based upon internalization and identification; and (2) a continuance (cognitive) conceptualization of commitment, which is based on compliance. Empirical findings from behavioral research suggest that commitment based upon social influence taps two distinguishable components-one for both internalization and identification, and the other for compliance [53, 67, 69].

\section{Research Model and Research Hypotheses}

THE RESEARCH MODEL, SHOWN IN FigURE 1, examines the effects of user commitment on volitional systems acceptance and usage behavior. Given the central role of the users' psychological attachment in determining systems usage behavior in our model (in contrast to centrality of subjective and social norms in prior research), we call it the Psychological Attachment Model (PAM).

The relationships shown in Figure 1 as H1a, H1b, H1c, and H1d have been examined in prior technology acceptance and use research on social influence [40, 70, 71]. We expect that they will also be supported in the current research. Therefore, we hypothesize that:

Hla: Perceived usefulness will have a positive influence on attitude toward using the system.

HIb: Perceived ease of use will have a positive influence on attitude toward using the system.

HIc: Perceived usefulness will have a positive influence on behavioral intention to use the system.

HId: Attitude toward system use will have a positive influence on behavioral intention to use the system.

The proposed model builds upon our understanding of systems acceptance and use based upon personal norms and social norms. Whereas personal norms and affective processes underlie identification and internalization of systems usage behavior, social norms and cognitive processes underlie compliance of such behavior. The fol- 


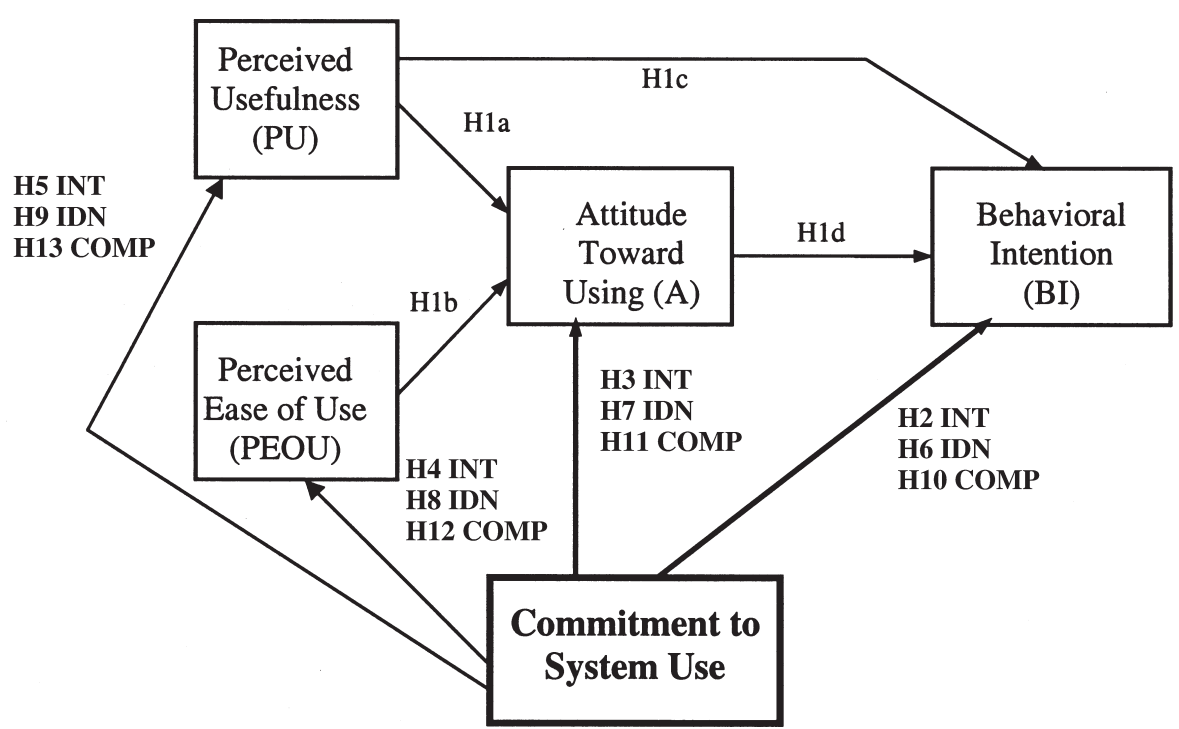

Figure 1. The Psychological Attachment Model: The Multidimensional Commitment Model of Volitional System Adoption and Use

lowing discussion explains how affective and continuance commitments influence system users' acceptance and usage behavior.

\section{Hypotheses About Affective Commitment}

Affective commitment refers to the commitment of the system user based upon congruence of personal values and identification of satisfying self-defining relationships. Given their psychological attachment to, identification with, and involvement in, organizational work behaviors, system users feel and believe that the use of the new system is the "right thing" to do. System users' internalization of the induced behavior is motivated by the congruence of values they associate with its use. Their identification with the induced behavior is motivated by the self-satisfying relationships they seek to establish or maintain with "influencers" (managers, system champions, or other users of the systems).

\section{Internalization-Based Commitment}

Internalization involves adoption of the induced behavior by the system user based upon its perceived congruence with one's own personal norms and values. The question arises if users accept the induced usage behavior - the ideas and actions of which it is composed-as intrinsically rewarding or congruent with their value system. Kelman clarifies that these criteria for internalization can be achieved if system users consider it "useful for the solution of a problem or find it congenial to their needs" $[34$, p. 53]. This observation further substantiates the necessity for developing deeper 
understanding of organizational and behavioral contexts of user commitment related to social influence processes.

Systems usage behavior adopted through internalization tends to be integrated with an individual's existing values. The user derives satisfaction from internalization due to the content of the new behavior. Thus, regardless of an external mandate for systems usage, the person finds system use intrinsically rewarding, and works with the system because he wants to; the system enables him to do what he really wants to do [44].

Internalization, characterized by the highest level of psychological attachment to system use, is therefore expected to have a direct positive effect on attitude and behavioral intentions.

H2: Internalization will have a positive influence on users' behavioral intention to use the system.

H3: Internalization will have a positive influence on users' attitude toward the use of the system.

In their original proposal for developing a better understanding of social influence processes, Davis et al. made an important observation about the personal relevance of system use to usage behavior: "Users may be willing to tolerate a difficult interface in order to access functionality that is very important, while no amount of ease of use will be able to compensate for a system that doesn't do a useful task" [19, p. 1000]. Given intrinsic interest in self-satisfying use, users may perceive it as a solution to their problem or congenial to satisfaction of their needs. Hence, they are willing to invest greater effort in learning and using the system. Internalization of new systems usage behavior is therefore characterized by a positive influence on perceived usefulness and perceived ease of use of the system.

H4: Internalization will have a positive influence on users' perceived ease of use of the system.

H5: Internalization will have a positive influence on users' perceived usefulness of the system.

When the user adopts the induced behavior through internalization, she tends to perform it under conditions of personal relevance of such behavior, regardless of surveillance or salience [34].

\section{Identification-Based Commitment}

Like internalization, identification of system usage behavior derives from users' affective processes and personal norms and values. Identification is particularly relevant to the important question: What if users do not find the content of the induced behavior intrinsically rewarding? Through identification, users' affective processes and personal norms can still positively influence their usage behaviors. The system user, in this case, may actually believe in the associated behavioral response even 
though the specific content of the behavior is "more or less irrelevant" [34, p. 53]. The individual accepts the induced behavior because he wants to establish or maintain a satisfying self-defining relationship to another person or group.

In the case of internalization, the system user's values and norms related to organizational work performance primarily influence attitudes toward system use and behavioral intentions to use the system. In identification, the user's satisfaction derived from the salience of the desired relationship tends to have a similar effect on attitudes and intentions. Even though uninterested in the content of induced behavior, the person values the desired relationship; therefore, he feels that he should adopt the induced behavior.

H6: Identification will have a positive influence on users' behavioral intentions to use the system.

H7: Identification will have a positive influence on users' attitudes toward the use of the system.

Given the user's acceptance of the induced behavior because of the desired satisfying and self-defining relationship, acceptance of such behavior is volitional. Identification is therefore expected to positively influence perceived usefulness and perceived ease of use, even though the underlying motivation is different from internalization.

H8: Identification will have a positive influence on users' perceived ease of use of the system.

H9: Identification will have a positive influence on users'perceived usefulness of the system.

It is important to recognize that when the user adopts the induced behavior through identification, she tends to perform it only under conditions of personal salience of the relationship to others [34]. Identification therefore contributes to a user's selfimage based on perceived acceptance and recognition by others. However, the associated feeling of "obligation" distinguishes it from intrinsically rewarding behavior in internalization.

\section{Hypotheses About Continuance Commitment}

Continuance commitment is based on the costs that the system user associates with not adopting the induced behavior. Users with continuance commitment engage in the induced behaviors not because they feel it is the right thing to do or they want to do it. Rather, their primary focus is on rewards and punishments [34].

\section{Compliance-Based Commitment}

"Compliance can be said to occur when an individual accepts the induced behavior because he hopes to achieve a favorable reaction from another person or group" [34, $\mathrm{p}$. 53], conforming to gain rewards or approval, and minimize costs such as punishments 
or disapproval. Hence, in contrast to behavior underlying identification and internalization, behavior driven by compliance is not volitional [25, 33, 34]. Overt behavior satisfies the need for public conformity to induced behavior without its private acceptance by a user. Kelman observes that satisfaction derived from compliance is due to the "social effect of accepting influence" [34, p. 53]. Surveillance, required to sustain usage behavior induced through compliance, may be applied through a variety of technical, administrative, or managerial controls $[12,38]$. Hence, in the case of compliance, induced behavior is seen as controlling and pressurizing by the user, and has a negative influence on user intentions and attitude.

H10: Compliance will have a negative influence on users' behavioral intention to use the system.

H11: Compliance will have a negative influence on users' attitude toward the use of the system.

When exercising compliance, users are not adequately motivated to do what the system may enable them to do [44]. It is also possible that such systems may make it harder to do what they are really motivated to do [44]. In contrast to the social normative compliance focus in prior research, absence of perceived usefulness may be more apparent in case of self-determined volitional system usage activities. It is all the more likely to happen if such activities are perceived by the system user as irrelevant or as unnecessary obstacles in fulfilling self-valued goals [40]. With an apparent lack of perceived usefulness, users may not be motivated enough to invest time or effort in learning or using such capabilities. Therefore, even despite superb technical capabilities or user interfaces, such systems may create challenging problems of user acceptance [44].

H12: Compliance will have a negative influence on users' perceived ease of use of the system.

H13: Compliance will have a negative influence on users' perceived usefulness of the system.

As mentioned above, compliance results from the "costs" that the user associates with not engaging in the specific behavior. For specific, discrete, prespecified, predetermined, and easily measurable activities (such as transaction "volume") subject to reliable surveillance, compliance may yield the desired "overt behavior" [34]. However, for volitional system usage activities, overt behavior (such as typing data in an input screen) may be an inadequate proxy for self-determined and volitional usage behavior (such as in a communication, coordination, and collaboration system, providing meaningful information or sharing valuable knowledge). This line of reasoning seems consistent with recent empirical findings that have reported inconclusive results about social influence [40]. As enforcement of compliance may not always be desirable, feasible, or economical for volitional systems usage activities, the realization of usage behavior is even more critically dependent upon the self-will of the users. 
Summary of Hypothesized Relationships

The literature contrasts affective commitment (based upon personal norms and affective processes) and continuance commitment (based upon social norms and cognitive processes). Internalization is driven by congruence of a user's values and personal norms with the induced usage behavior. Identification is based upon his volition for satisfying and self-defining relationships through adoption of such behavior. These two types of commitment, based upon affective behavioral processes and personal norms, are hypothesized to have positive influence on users' attitudes, intentions, perceived usefulness, and perceived ease of use. In contrast, under compliance (or continuance commitment) users adopt specific behaviors not because they feel it is the right thing to do or they want to do it. Rather, they expect to gain specific rewards or approval and avoid specific punishments or disapproval by conforming. When users accept such behaviors through compliance, they perform it only under conditions of surveillance by the influencing agent. Particularly, in the case of volitional system usage activities, wherein such surveillance may be infeasible or uneconomical, compliance may be difficult to enforce. Given the perceptions of being controlled and pressured, compliance is expected to have a negative influence on users' attitude, intentions, perceived usefulness, and perceived ease of use.

\section{Research Methodology}

ORGANIZATIONAL SYSTEM USE IS OFTEN INTEGRATED with the context of organizational work, and researchers recommend understanding it within those contexts [2, $16,71,77]$. This field study focused on understanding usage behavior in the context of a system implementation at two points in time: after initial adoption and use (called the adoption stage), and after extended use over six months (called the use stage).

\section{Organizational Context of Volitional Systems}

\section{Acceptance and Usage}

As noted earlier, in recent years, organizations have started implementing new types of information and communication systems that depend upon volitional systems usage behavior. Many such systems have been the subject of recent research related to volitional communication, collaboration, and coordination systems usage activities $[2,29,41,42,43,63]$. One such organizational system, being implemented at a large health-care organization in the Midwestern United States, was the target focus of the current study.

The new system was intended to provide a superior technological substitute for self-determined activities of communication, collaboration, and coordination executed previously with a medley of e-mail, phone, and paper-based systems. As the usage of this system and the specific activities were not mandated, they represent an archetype of volitional system usage activities relevant to the current research. None of these system usage activities were a part of any functional, role-based, or task-focused 
work-related activity or were governed by any implicit or explicit promise of incentives or threat of punishment. The usage of the system and its activities was thus totally self-determined.

In highly publicized meetings, senior managers shared the vision of greater productivity, better service quality, and lower costs anticipated from the implementation of the new system. Employees registered through an automated phone system for any one of several training sessions convenient to them. They were not provided any incentive for attending the training nor was any threat of punishment evident for not attending the training. The managers prespecified the system usage activities related to communication, collaboration, and coordination that they anticipated as most relevant to system performance. ${ }^{1}$ These specific usage activities were the primary focus of initial training at the time of adoption and also for subsequent system use at work. The nonmandated and self-chosen use of these activities distinguishes this study from prior research, which focused on managerial compliance.

\section{Procedure and Data Sample}

Distribution and collection of survey questionnaires for both phases was coordinated with the help of the organizational CIO's office, the system administrator, and the professional trainers. The first set of precoded questionnaires was administered after a two-hour hands-on training session. The instructors noted the user codes against respective trainee names on the rosters that facilitated tracking of anonymous responses across both phases. Survey respondents were solicited from a pool of 714 employees from different functions and different organizational levels. The initialadoption phase yielded 590 usable responses.

After six months of system use, an extended-use survey was sent to 500 subjects whose current contact information was available from training rosters. The system administrator coordinated the distribution and collection of the survey. By a fourweek deadline, 200 responses were received, yielding 179 usable matched responses for the two phases. Analysis of the two samples (described in Appendix A) revealed no significant differences in the composition of users.

\section{Measurement Scales}

Standard guidelines for questionnaire design, item development, and data collection were followed [13, 22]. The measurement scales for perceived usefulness, perceived ease of use, attitude, and behavioral intention were adapted from Davis [17, 18]. To measure commitment, we used an adaptation of the commitment scale developed by O'Reilly and Chatman [52], and empirically validated in several studies [7, 52, 69]. Items within the same construct were randomized to prevent systematic response bias. Instrument pretesting was done with selected users from the same company and included research scientists, managers, and professional trainers. Pilot testing enabled improvements in reliability and validity for examining the research model. 


\section{Data Analysis and Findings}

\section{Psychometric Properties of Measures}

THE MEASUREMENT SCALES DEVELOPED in accord with Churchill [13] exhibited acceptable psychometric properties, as demonstrated in Appendix B. All scales exhibited high internal consistency reliability, with 0.70 used as the lower cutoff [51]. Construct validity was supported by principal components and maximum-likelihood analyses using both varimax and oblimin rotations with 0.35 as the lower cutoff.

Examination of "within-construct" and "cross-construct" correlations supported the criteria for convergent and discriminant validity $[4,10]$. In line with standard procedures for multitrait-multimethod analysis, multiple methods of measurement were used for each construct. The factor analysis of the independent and dependent variables suggested that the variables within the same constructs were more strongly correlated than variables across different constructs. Given negligible instances where cross-construct correlations were greater than within-construct correlations, discriminant validity was supported.

Based upon the theoretical model and analysis of survey data, the measures were found to behave as expected in relation to other constructs, thus supporting predictive validity $[13,72]$. The domain for the various constructs is defined in terms of the underlying theory and research satisfying content validity criteria [13]. Refining the instrument through pretesting and pilot testing of typical respondents [78] satisfied face validity criteria.

The study is expected to demonstrate nomological validity (based on a formal theoretical network) by providing empirical evidence about the measures' suggested behavior [15]. The extended-use sample was found comparable with the initial-adoption sample in terms of demographics as well as reliability and validity of all measures.

\section{Measures for Commitment to System Use}

The discussion in the prior sections distinguished between affective commitment (internalization and identification) and continuance commitment (compliance). As stated earlier, the former is based largely on affective processes and personal norms, the latter upon social norms and a cognitive "calculative" focus on minimizing costs of nonperformance of induced behavior. The centrality of system users' own beliefs versus how those beliefs "conform" to others' beliefs distinguishes affective from continuance commitment. Empirical findings from behavioral research (e.g., [53, 67, 69]) on Kelman's social influence processes affirms that (resulting) commitment indeed taps these two distinct components.

Consistent with theoretical and empirical observations in behavioral research, scree plots and principal component analysis for commitment yielded two distinct factors for both phases, one each for affective (internalization and identification) and continuance (compliance) dimensions (shown in Table 2). 
Table 2. Factor Structures for Commitment Constructs: Comparing Initial Adoption and Extended Use (Rotation Component Matrix)

Factor Analysis for Initial Adoption Data $(n=526)$

\begin{tabular}{lcc}
\hline & \multicolumn{2}{c}{ Component } \\
\cline { 2 - 3 } & 1 & 2 \\
\hline INT3 & 0.843 & \\
IDEN1 & 0.839 & \\
IDEN2 & 0.749 & \\
INT2 & 0.725 & \\
INT1 & 0.701 & \\
IDEN3 & 0.664 & 0.820 \\
COMP1 & & 0.757 \\
COMP3 & & 0.754 \\
COMP2 & 0.674 \\
COMP4 & & \\
Factor Analysis for Extended Use Data $(n=148)$ \\
\hline INT3 & 0.856 & \\
IDEN1 & \\
IDEN3 & 0.847 & \\
INT2 & 0.796 & \\
INT1 & 0.778 & \\
IDEN2 & 0.759 & \\
COMP1 & 0.736 & 0.849 \\
COMP4 & & 0.809 \\
COMP3 & & 0.288 \\
COMP2 & & \\
\hline
\end{tabular}

Notes: Extraction method: principal component analysis. Rotation method: varimax with Kaiser normalization. Rotation converged in three iterations.

For the initial-adoption analysis, the various components of affective commitment and continuance commitment exhibited distinct loading patterns. The two distinct factors accounted for 60.33 percent of the variability of the original measures. The correlation matrix containing the Pearson correlations (shown in Table 3) affirms the presence of high correlations of measures within the two factors and low correlations across factors.

The reliability of the affective commitment (identification and internalization) items was 0.856 for the initial-adoption phase and 0.892 for the extended-use phase. For the extended-use phase, affective commitment accounted for 57.49 percent of the variability of the original measures. For both phases, the reliability of the "combined" identification-internalization composite measure is higher than the reliability of each considered separately.

For the extended-use analysis, all six measures of affective commitment (identification and internalization) loaded together. For continuance commitment, compliance 


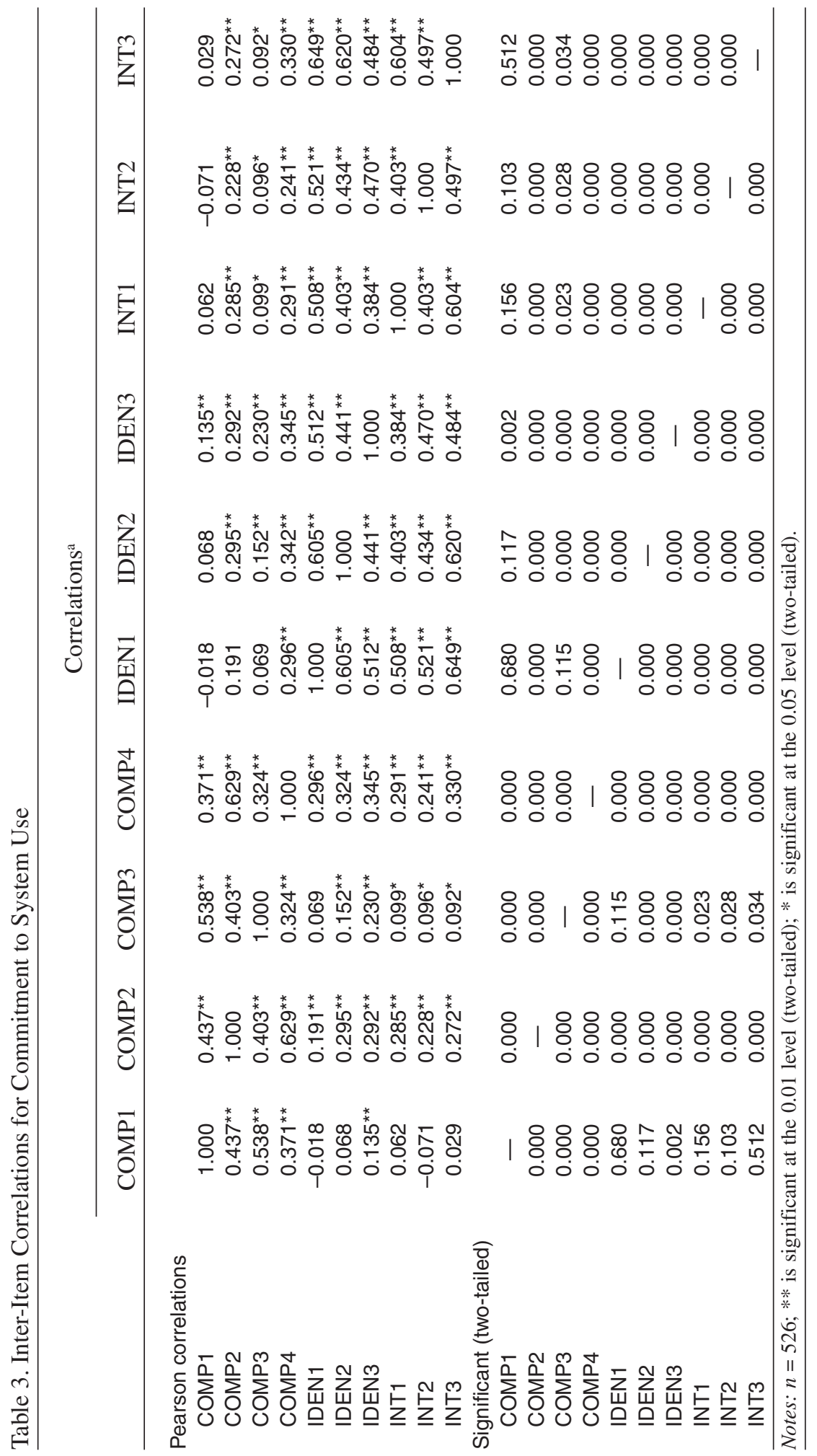


items COMP1, COMP3, and COMP4 loaded together on a single factor. However, compliance item COMP2 exhibited almost equal loading $(0.268$ for affective and 0.288 for continuance) on both the affective and continuance factors. A review of the correlation matrix for the extended-use analysis confirmed these observations. All items for internalization and identification exhibited high correlations, with other items ranging between 0.388 and 0.800. However, for compliance, only items COMP1, COMP3, and COMP4 exhibited high to moderate correlations ranging between 0.547 and 0.234 . Particularly, correlations of COMP2 with COMP1 (0.130) and COMP3 (0.016) were inordinately low. For the specific context of study, item COMP2 seems to capture some elements of social normative compliance as well as some elements of internalization and identification. Hence, for the extended-use analysis, compliance item COMP2 was excluded to improve reliability of the overall continuance (compliance) measure. The resulting scales for continuance (containing three items for compliance) and affective (containing six items for internalization and identification) commitments were then used for examining the hypothesized relationships.

The proposed model theorizes main effects for all determinants. Given predicted linear relationships, multiple hierarchical regression was used for analyzing hypothesized relationships. The regression models assess how well the different "levels" of commitment explained behavioral intention to use the system. Assumptions of normality and absence of intercorrelations among independent variables were affirmed with SPSS diagnostics including graphical plots, Durbin-Watson statistics, and collinearity statistics. The analyses of hypotheses shown in Table 4 provide substantial support for the proposed relationships in the model.

\section{Explaining Behavioral Intention to Use the System}

The research model for matched samples explained 58.5 percent of the variance in behavioral intentions to adopt and 47.5 percent of the variance in intentions to use the system (Table 4). Perceived usefulness was found to have a strong positive influence on user intentions for both stages, with attitude having a secondary positive influence only at initial use (H1c).

As theorized, affective commitment (identification and internalization) was found to have a significant positive influence on users' intentions to use the system $(\mathrm{H} 2$ and H6) while compliance was found to have a negative effect (H10). For both types of commitment, these effects were supported for extended use of the system, whereas no effect was apparent for initial use.

Perceived usefulness was found to have a sustained positive significant influence on user intentions; however, the effect of attitude on intention seems to vanish with extended system use. Instead, internalization, identification, and compliance emerged as additional determinants of intention. As hypothesized, affective commitment had a positive effect, whereas continuance commitment had a negative effect on intentions. Hence, user commitment appeared to have an increasingly significant and direct influence on intention to use the system after extended use. 
Table 4. Regression Results for the Hypothesized Relationships

\begin{tabular}{ccc} 
Initial & Initial & Extended \\
adoption & adoption & use \\
$n=590$ & $n=179$ & $n=179$ \\
\hline
\end{tabular}

Explaining intention to use $(\mathrm{H} 1 \mathrm{c}, \mathrm{H} 1 \mathrm{~d}, \mathrm{H} 2, \mathrm{H} 6, \mathrm{H} 10)$

Supported: H1c, H1d (initial), H2 (extended), H6 (extended), H10 (extended)

$\begin{array}{lccc} & \text { Adj. } R^{2}=0.441 & \text { Adj. } R^{2}=0.585 & \text { Adj. } R^{2}=0.475 \\ \text { Perceived usefulness (H1c) } & 0.593^{\star * *} & 0.693^{\star \star *} & 0.598^{\star \star *} \\ \text { Attitude }(\mathrm{H} 1 \mathrm{~d}) & 0.168^{\star \star *} & 0.152^{\star *} & - \\ \text { Internalization }(\mathrm{H} 2) & & & \\ \text { Identification }(\mathrm{H} 6) & - & - & 0.179^{\star *} \\ \text { Compliance }(\mathrm{H} 10) & - & - & -0.205^{\star \star \star}\end{array}$

Explaining attitude to use $(\mathrm{H} 1 \mathrm{a}, \mathrm{H} 1 \mathrm{~b}, \mathrm{H} 3, \mathrm{H} 7, \mathrm{H} 11)$

Supported: $\mathrm{H} 1 \mathrm{a}, \mathrm{H} 1 \mathrm{~b}$ (initial), $\mathrm{H} 3$ (initial), $\mathrm{H} 7$ (initial); not supported: $\mathrm{H} 11$

$\begin{array}{lccc} & \text { Adj. } R^{2}=0.142 & \text { Adj. } R^{2}=0.346 & \text { Adj. } R^{2}=0.052 \\ \text { Perceived usefulness (H1a) } & 0.168^{\star \star *} & - & 0.238^{\star \star} \\ \text { Perceived ease of use (H1b) } & 0.145^{\star *} & 0.302^{\star \star \star} & - \\ \text { Internalization }(\mathrm{H} 3) & & & - \\ \text { Identification }(\mathrm{H} 7) & 0.187^{\star \star *} & 0.394^{\star \star \star} & - \\ \text { Compliance }(\mathrm{H} 11) & - & - & -\end{array}$

Explaining perceived ease of use $(\mathrm{H} 4, \mathrm{H} 8, \mathrm{H} 12)$

Supported: H4, H8, H12

Internalization $(\mathrm{H} 4)$

$\begin{array}{ccc}\text { Adj. } R^{2}=0.126 & \text { Adj. } R^{2}=0.226 & \text { Adj. } R^{2}=0.144 \\ 0.348^{\star \star \star} & 0.542^{\star \star \star} & 0.394^{\star \star \star} \\ -0.283^{\star \star \star} & -0.216^{\star \star} & -0.219^{\star \star}\end{array}$

Compliance $(\mathrm{H} 12)$

$-0.283$

Explaining perceived usefulness $(\mathrm{H} 5, \mathrm{H} 9, \mathrm{H} 13)$

Supported: H5, H9, H13 (initial)

$\begin{array}{lccc} & \text { Adj. } R^{2}=0.188 & \text { Adj. } R^{2}=0.248 & \text { Adj. } R^{2}=0.148 \\ \text { Internalization (H5) } & 0.470^{\star \star *} & 0.556^{\star * \star} & 0.412^{\star *} \\ \text { Identification (H9) } & -0.180^{\star * *} & -0.152^{*} & - \\ \text { Compliance (H13) } & & -\end{array}$

Notes: While internalization and identification loaded together as one factor, compliance loaded separately as the second distinguishable factor. The contrast between the two factors is discussed in theory development and research model in terms of affective and continuance dimensions of commitment. Data presented for cross-sectional, between-subjects, and within-subjects comparison. $* p<0.05, * * p<0.01 ; * * * p<0.001 . \beta=$ standardized regression coefficient.

\section{Explaining Attitude Toward Use of the System}

The research model for matched samples explained 34.6 percent of the variance in attitude at time of adoption and 5.2 percent of the variance in attitude over extended use (Table 4). User commitment based upon internalization and identification had the 
strongest positive effect on attitude, as hypothesized ( $\mathrm{H} 3$ and $\mathrm{H} 7)$. Both perceived usefulness (H1a) and perceived ease of use (H1b) had strong secondary positive influence on attitude at initial system use. For extended use, perceived usefulness was the only statistically significant determinant but explained negligible variance in attitude (5 percent). Compliance did not exhibit the expected negative effect on attitude at initial or extended use (H11). These findings are further explained in the Discussion section.

\section{Explaining Perceived Ease of Use}

The research model explained 22.6 percent of the variance in system users' perceived ease of use at adoption and 14.4 percent on extended system usage (Table 4). As hypothesized, identification and internalization were found to have a sustained positive influence on perceived ease of use (H4 and H8). Also, as expected, compliance was found to have a sustained negative influence at initial use and after extended use (H12).

\section{Explaining Perceived Usefulness}

The research model explained 24.8 percent of the variance in system users' perceived usefulness of the system at adoption and 14.8 percent after extended use (Table 4 ). As hypothesized, identification and internalization were found to have a sustained strong positive influence on perceived usefulness (H5 and H9). However, compliance seemed to have a negative effect on perceived usefulness only at initial use (H13). Interestingly, compliance did not appear to have any statistically significant influence on perceived usefulness after extended use.

\section{Summary}

The proposed research model explained between 44.1 percent and 58.5 percent of the variance in intentions to use the system for the three samples. Affective commitment (identification and internalization) had a sustained positive influence on perceived usefulness and ease of use from initial adoption to extended usage. Affective commitment also positively affected user attitude at initial system use and behavioral intentions over extended use. In contrast, continuance commitment (compliance) negatively affected perceived usefulness and perceived ease of use at initial system use, and behavioral intentions and perceived ease of use over extended use. The effects of different "levels" of user commitment (arising from Kelman's [34] social influence processes) on behavioral intentions, perceived usefulness, perceived ease of use, and attitudes at initial and extended system use are summarized in Table 5.

\section{Discussion}

FORMERLY, ORGANIZATIONAL IS WERE USED primarily to enforce managerial compliance for the execution of specific activities. However, in recent years, organizations 
Table 5. How Social Influence Processes Affect Volitional System Adoption and Use: Proposed Multidimensional Model of System User Commitment

\begin{tabular}{|c|c|c|c|c|c|c|c|c|}
\hline & \multicolumn{4}{|c|}{ Initial adoption } & \multicolumn{4}{|c|}{ Extended use } \\
\hline & PU & PEOU & A & BI & PU & PEOU & A & BI \\
\hline $\begin{array}{l}\text { Affective commitment } \\
\text { Identification } \\
\text { Internalization }\end{array}$ & + & + & + & & + & + & & + \\
\hline $\begin{array}{l}\text { Continuance commitment } \\
\text { Compliance }\end{array}$ & - & - & & & & - & & \\
\hline Perceived usefulness & & & + & + & & & + & + \\
\hline Perceived ease of use & & & + & & & & & \\
\hline $\begin{array}{l}\text { Attitude toward } \\
\text { system use }\end{array}$ & & & & + & & & & \\
\hline
\end{tabular}

have started implementing new types of information and communication systems that do not conform to this behavioral logic. Specifically, several studies have confirmed that such systems for self-directed knowledge use, sharing, creation, and renewal often fail because of lack of user commitment. Researchers and practitioners also recognize that acceptance and usage of these new types of systems critically depend upon users' volitional behavior. However, our sparse understanding of volitional usage behavior, and negligible awareness about the volitional nature of user commitment, have made it difficult to advance theory, research, and practice on this issue. In response, the current research develops the first known theoretical, psychometric, and empirical understanding of how volitional usage behavior is affected by user commitment.

The proposed research model was developed around Kelman's [34] theory of social influence and related processes of internalization, identification, and compliance. The proposed construct of commitment to system use and the psychological attachment model were validated empirically in a real organizational implementation from initial system adoption to extended use. Our findings suggest that user commitment to volitional systems adoption and usage depends upon personal norms and affective processes besides social norms and cognitive processes examined in prior IS acceptance research. The proposed model integrates the missing dimensions of affective processes and personal norms that are critical to the realization of internalization and identification of induced systems usage behavior. The proposed multidimensional commitment model develops a more precise understanding of the cumulative influence of affective and continuance commitment on systems usage behavior. Theory development based upon Kelman's social influence framework offers new empirical insights about system users' commitment and how it affects volitional usage behavior. 


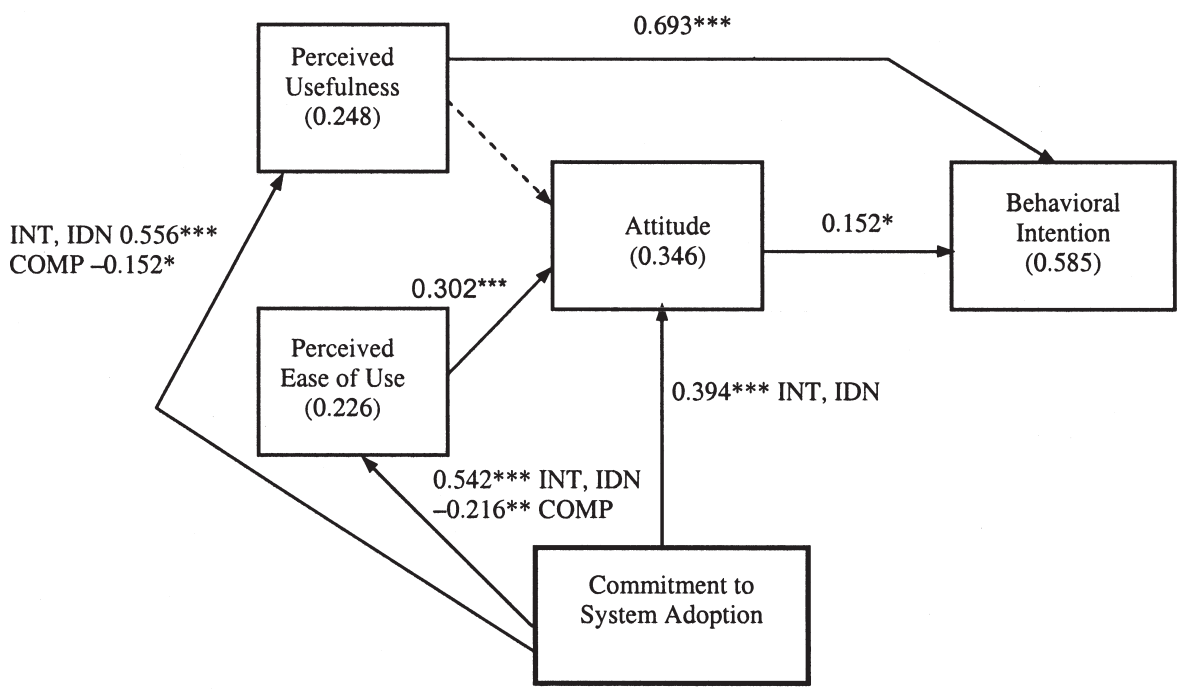

Figure 2. The Multidimensional Commitment Model of Volitional System Adoption Notes: Only significant relationships are shown. Numbers represent standardized regression coefficients. Variance explained in dependent variables is shown in parentheses. ${ }^{*}$ significant at $p<0.05 ; * *$ significant at $p<0.01 ; * * *$ significant at $p<0.001$.

\section{Findings About System Acceptance and Use}

Two major dimensions of commitment were found to be significant predictors of volitional system adoption and usage. Compliance was distinguished in terms of continuance commitment, whereas identification and internalization were both distinguished in terms of affective commitment. The hypothesized influence of user commitment on system users' behavioral intention and attitude were analyzed at two stages: after initial adoption and after extended use of the system for six months at work. The contrasting set of statistically significant relationships is delineated in Table 4 and depicted in Figures 2 and 3.

A comparison between Figures 2 and 3 suggests interesting contrasts between how user commitment influences behavioral intentions at initial adoption and over extended system use. Understanding the differences between adopters and users may possibly suggest appropriate managerial and social influence strategies to promote user commitment for both stages.

Perceived usefulness and attitudes are the primary determinants of intentions to adopt the system. For adopters, affective commitment (both internalization and identification) has indirect positive influence on behavioral intentions through attitude, perceived ease of use, and perceived usefulness. However, continuance commitment (compliance) has a negative influence on behavioral intentions indirectly through perceived ease of use and perceived usefulness.

Besides having a firm basis in theory, these findings also have intuitive appeal. Without prior exposure to the system, the adopter is preconditioned by cognitive be- 


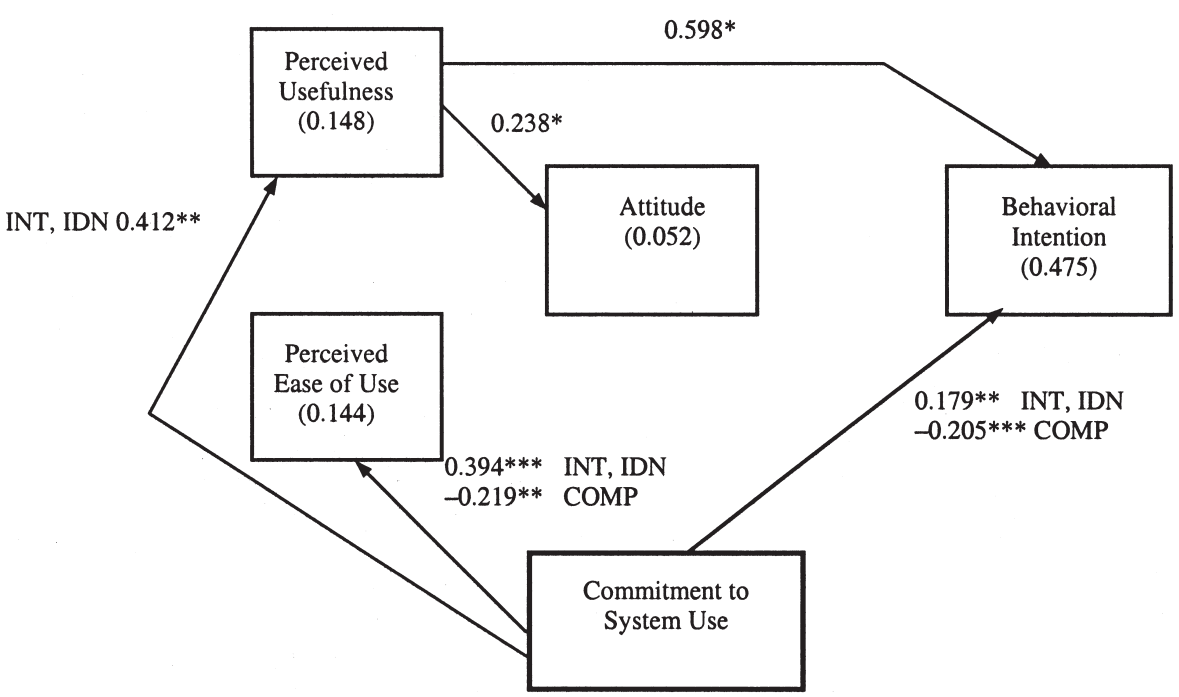

Figure 3. The Multidimensional Commitment Model of Volitional System Use

Notes: Only significant relationships are shown. Numbers represent standardized regression coefficients. Variance explained in dependent variables is shown in parentheses. ${ }^{*}$ significant at $p<0.05 ; * *$ significant at $p<0.01 ; * * *$ significant at $p<0.001$.

liefs about the system and how it may be useful. Personal norms tend to motivate system adoption in alignment with personal values and beliefs and personal salience of relationships. In contrast, social norms characterized by the "motivation to comply" tend to minimize "costs" associated with adoption of the new system. Moreover, perceptions about ease of use are important for initial adoption. Whereas personal norms have positive influence on such perceptions, external pressures to comply tend to have a negative effect. During initial adoption, psychological attachment to system use does not have a direct effect on behavioral intentions. It is likely that at this stage, the user may not have adequate firsthand exposure to system use to influence intentions significantly.

However, with extended use of the system, the user develops a strong psychological attachment (or its converse in the case of compliance) with sustained use. Hence, commitment tends to affect intentions directly. Besides commitment, perceived usefulness is the other determinant of behavioral intentions at this stage. Internalization and identification have a direct positive influence on behavioral intentions, whereas compliance has a direct negative influence, as predicted. It seems that the greater the psychological attachment users develop for system use, the more they perceive it as useful to them and the more they want to use it. Given a greater psychological attachment to system use, they apparently perceive its use as more personally meaningful. Consequently, perceptions about ease of use become less relevant as determinants of system use. Also, prior cognitive beliefs embedded in attitudinal considerations assume a lesser role in affecting behavior as a richer set of affective beliefs based on personal norms and values gain strength. 
Interestingly, for both adopters and users, compliance does not seem to have any direct influence on attitude. This seems to result from the lesser role of social influences and social norms in affecting attitude toward volitional system usage activities. In contrast to enforced compliance in prior studies that have examined mandated usage, this study's focus is on usage behaviors that are volitional and not mandated. Therefore, at initial adoption, compliance may have indirect negative influence on attitude through perceived ease of use. However, over extended system use, perceived ease of use becomes less significant, as noted before.

\section{Theoretical Contributions and Implications}

Divergent theoretical perspectives of social influence to conceptualize and measure user commitment in prior IS research have led to inconclusive empirical findings. In response, this study builds upon substantial organizational and behavioral research on Kelman's social influence processes focused on commitment. Integration of the system user's affective processes and personal norms in our model brings users' own beliefs to center stage. In prior research, these were lost in the shadows of conformance to others' beliefs. This is an important distinction, given users' more volitional and autonomous roles in systems oriented toward communication, coordination, and collaboration activities. This study refocuses attention on the origin of users' behaviors, an issue of growing interest in systems implementation research $[28,44,54,66]$.

A lack of support for social influence in prior studies (e.g., [40]) may have resulted from not considering affective processes and personal norms. It may also have resulted from a purely cognitive focus on social norms. While developing new understanding about volitional usage, this research also develops a theoretically consistent empirical foundation for reconciling inconclusive findings about social influence in prior research.

Previous studies have attributed missing support for social influence to specific roles such as college faculty and their use of the Web for sharing knowledge. However, our research suggests a contrasting focus on volitional usage behavior that may be associated not necessarily with specific roles but with personal dispositions about volition and choice. The current study aids in understanding why, based upon their personal norms and social norms, system users may choose to conform to social influence (or not). This perhaps also explains why, even within the same roles, users may sometimes exhibit different levels of commitment based upon volitional acceptance and usage behaviors. Generally, the various types of commitment may be present in the system user and have differential influences on intentions. Examination of how social influence affects usage behavior should therefore focus on both continuance and affective categories of commitment.

Many prior studies [40,70] have focused on individual-level task-specific systems that had to be used for performing mandated tasks even when there was a choice of which system to use. Given the necessity of using one system or another for performing mandated tasks, users seldom had a choice of not using any of the systems. Absence of a real choice thus diminished the users' autonomy, as they felt pressured by 
built-in technical, administrative, or managerial controls [12,38]. Such archetypes of hierarchical command-and-control systems focus on seeking compliance, with primary emphasis on users" "motivation to comply."

In contrast, our focus is on volitional system usage activities of communication, collaboration, and coordination. Our findings are consistent with research literatures that have highlighted an active and engaged role of the system user for using, sharing, creating, and renewing knowledge. Such system usage activities are dependent upon users' volitional behavior guided by personal norms and values [20]. The volitional nature of such activities makes systems usage critically dependent upon users' commitment in general, and internalization and identification in particular.

\section{Practical Implications}

Markus and Keil have argued that "systems do not improve organizational performance or create business value; users and their managers do" [44, p. 24]. The effect of managerial and social influence is realized through users' internalization, identification, and compliance of induced behavior. Systems designed for support of collaboration, coordination, and communication can facilitate teamwork and increase individuals' interactions with others [2]. Despite their technical sophistication, such systems may, however, not be used to advantage unless the users want to or believe that they should. Even for a relatively simple system such as the Navy/Marine Corps Intranet described earlier, implementation became impossible as the users become passionate about not using it. Success of such systems thus depends upon users' "volition" for system use. User commitment has therefore become a key concern for managers implementing such systems [23, 39].

Responding to such concerns, this study develops and validates a user commitment construct with a central focus on volitional behavior and examines how it affects system adoption and usage behavior. We find that, besides social norms, users' values and personal norms play a key role in affecting their usage behaviors. The observed contrast between affective commitment (internalization and identification) and continuance commitment (compliance) facilitates resolution of prior theoretical and psychometric problems and offers new insights. The current research also confirms prior findings that peer recognition (identification) is an effective motivator for knowledge workers' volitional system use [76].

An important implication is how systems usage can be understood as a function of user roles and usage activities, both of which may influence commitment. As observed by Davis et al. [19], precise understanding of the effects of social influence is feasible only by developing better understanding of usage contexts. In this respect, the sociopsychological and behavioral aspects of commitment are an important contribution of this research, as they help define the usage context. Such contexts are relevant as users committed to performance outcomes that "really matter" to them diligently use the systems for personally meaningful and personally rewarding goals. Devoid of those contexts, such activities could seem meaningless or trivial to users. 
Therefore, consideration of user commitment is a prerequisite and not an afterthought for successful system implementation. Designers and champions need to focus on what users expect from system use. Effective system design thus depends upon keen awareness of the organizational context within which commitment to system use makes sense to users. Even a simple, easy-to-use system could fail to deliver results if users do not perceive it as useful in achieving what they perceive as their real goals $[19,34,44]$. Such goals may be intrinsically rewarding for the users or may provide a means for establishing or maintaining satisfying self-defining relationships. When system usage is defined in harmony with users' needs for intrinsically rewarding and self-defining activities, induced behavior based upon affective commitment occurs naturally. However, if the induced behavior is enforced through compliance on recalcitrant users, only feigned (overt) behaviors might be achieved.

Therefore, the effectiveness of rewards and incentives emphasized in system usage research $[2,16,54]$ is at best uncertain. In designing organizational rewards and incentives, managers must ensure that the users' needs for internalization and identification are closely met while their needs for compliance are minimized. The primary focus must remain on developing users' personal norms and values related to intrinsically rewarding and self-defining attributes, and incentives should be designed to facilitate this process.

The model in this paper recognizes that "usage is only a necessary but not sufficient condition for realizing performance improvements due to information technology; if a system is not really useful (even if users perceive it to be) it should not be "marketed' to users" [19, p. 100]. It also covers the more common situation in practice wherein a system is really useful, but users do not perceive it to be [44]. Better understanding about affective commitment processes could bridge both types of disconnects between the availability of the system and its adoption and use.

\section{Limitations and Future Research}

The study represents an early attempt at theoretical conceptualization and validation of a user commitment construct for volitional usage and its effects on behavioral intentions of users. As with all research that is first to define, measure, and validate new constructs, this study has certain limitations that must be addressed in future research.

The study's sample is limited to users in a specific health-care services organization using a particular type of system for volitional usage activities of communication, collaboration, and coordination. As such, future replications of the research model are needed for generalizing the proposed user commitment construct and its effects on usage behavior for other systems and in other organizational contexts.

Future research is also needed to determine if the hypothesized effects about volitional usage behavior are applicable across different types of information systems other than the one discussed in this study. Measures and constructs proposed in this research can be adapted and applied in transaction-focused, individual-use systems, 
and future research should determine the generalizability of the relationships to other contexts.

Strategic activities of top management should also be examined. In the current study, top management's highly publicized communications informed the users in advance about the needs and benefits of the new system. Moreover, senior executives had prespecified the specific system usage activities that were expected to contribute to performance. Three categories of activities that were prespecified related to communication, collaboration, and coordination. Future research should also examine if such actions forming the texture of the organizational context in any way influenced systems adoption and usage behavior.

The users' beliefs, attitudes, and intentions are dynamic and not static from initial adoption to extended use. Therefore, the findings of this study should be viewed only as preliminary evidence of how the three commitment processes influence usage behavior at initial adoption and after extended system use. Longitudinal examination of the three processes would provide a more rigorous test of how commitment affects intention over time. Future research is also required to extend the findings from system adoption and system use to actual knowledge processes, such as knowledge use, sharing, creation, and renewal.

Prior research and practice on systems implementation have emphasized incentives for gaining user commitment $[2,16,54]$. Given the proposed theory and related empirical findings about continuance commitment, this emphasis should be reassessed. It would be interesting to determine if specific incentives may have an undermining effect on commitment, despite their popularity with practitioners and researchers. As our model predicted, we found a sustained negative influence of compliance (based on rewards and punishments) in contrast to sustained positive influence of both internalization (based upon congruent personal values) and identification (based upon satisfying self-identifying relationships) on users' intentions.

\section{Conclusions}

BOTH RESEARCH AND PRACTICE UNDERSCORE the importance of realization of user commitment to volitional system adoption and use. A more autonomous and selfdetermined role of system users is recognized in volitional systems usage activities of communication, collaboration, and coordination. This makes implementation of systems dependent upon volitional usage behavior particularly challenging. Sparse focus on users' own beliefs in contrast to the influencers' beliefs in prior research has provided a one-sided view of social influence. In response, this study developed user commitment constructs based upon users' own beliefs, and examined how they affect usage behavior. Given that such activities are at the crux of knowledge use, sharing, creation, and renewal for many contemporary systems, it is important to further advance this stream of research.

The proposed theoretical constructs and the research model were empirically examined in a real-world organizational systems implementation. Validation of the research 
was done with cross-sectional, between-subjects, and within-subjects data collected from 714 system users at the time of initial adoption and after its extended use for six months at work. The research model explained between 44.1 percent and 58.5 percent of the variance in adoption and usage behavior based upon direct effects of system user commitment. Findings suggest that user commitment plays a critical role in the volitional acceptance and usage of such systems. Affective (internalization and identification) and continuance (compliance) types of commitment demonstrated positive and negative influence, respectively, on user intentions as hypothesized.

Prior research has tried to understand internalization, identification, and compliance based on divergent theoretical perspectives of social influence with a purely cognitive focus on subjective norms. The stream of research has reported inconclusive findings, perhaps because of theoretical and psychometric problems observed for subjective norms. The current study attempts to offer conceptual clarity and theoretical consistency by representing user commitment in terms of Kelman's (1958) social influence processes. The study offers new insights about system acceptance and use, and resolves some of the previous inconclusive findings and psychometric difficulties. The multidimensional model of commitment should provide a more complete understanding of systems usage behavior for researchers and practitioners alike.

Note

1. Specific volitional system usage activities that were the focus of the current study included creating, addressing, and sending messages to communicate with others; creating and using distribution lists to send messages to multiple internal and external recipients; formatting message text for greater effect; reading and organizing incoming messages with the aid of archiving, filtering, and organizing capabilities; replying and forwarding messages to distribute information to others; attaching files to include in messages for distribution to others; creating calendaring and scheduling data for efficient time management; adding, modifying, and deleting appointments, events, and reminders to the personal event calendar and meeting scheduler; scheduling meetings with the aid of the meeting scheduler to check and confirm the availability of all participants; automation of specific messaging tasks for saving time; creation of custom views for display of needed information; use of online forms and public folders for sharing access to personal information with others; creation and organization of projects and tasks for prioritization of schedule; addition, organization, and personalization of contacts for contact management. None of the above system usage activities was mandated or required; users had complete choice of using none, any, some, or all of them.

Acknowledgments: The authors are grateful to the Editor-in-Chief and the three anonymous reviewers whose constructive and critical insights have contributed to improvements over the five revisions of this paper. The primary author acknowledges partial research support from the Snyder Innovation Management Research Center and the Center for Creation and Management of Digital Ventures at the Syracuse University Whitman School of Management.

\section{REFERENCES}

1. Ajzen, I. Nature and operation of attitudes. Annual Review of Psychology, 52 (2001), 27-58. 
2. Alavi, M., and Leidner, D.E. Review: Knowledge management and knowledge management systems: Conceptual foundations and research issues. MIS Quarterly, 25, 1 (March 2001), $107-136$.

3. Argyris, C. Empowerment: The Emperor's new clothes. Harvard Business Review, 76, 3 (May-June 1998), 98-105.

4. Bagozzi, R.P. Causal Models in Marketing. New York: Wiley, 1980.

5. Becerra-Fernandez, I., and Sabherwal, R. Organizational knowledge management: A contingency perspective. Journal of Management Information Systems, 18, 1 (Summer 2001), $23-55$.

6. Becker, T.E. Foci and bases of commitment-Are they distinctions worth making? Academy of Management Journal, 35, 1 (March 1992), 232-244.

7. Becker, T.E.; Randall, D.M.; and Riegel, C.D. The multidimensional view of commitment and the theory of reasoned action-A comparative evaluation. Journal of Management, 21, 4 (1995), 617-638.

8. Blau, P.M. Exchange and Power in Social Life. New York: Wiley, 1964.

9. Buchanan, B. Building organizational commitment: The socialization of managers in work organizations. Administrative Science Quarterly, 19, 4 (1974), 533-546.

10. Campbell, D.T., and Fiske, D.W. Convergent and discriminant validation by the multitraitmultimethod matrix. Psychological Bulletin, 569, 2 (March 1959), 81-105.

11. Charles, S.K. Knowledge management lessons from the document trenches. Online, 26, 1 (January-February 2002), 22-29.

12. Choudhury, V., and Sabherwal, R. Portfolios of control in software development projects. Information Systems Research, 14, 3 (September 2003), 291-314.

13. Churchill, G.A., and Iacobucci, D. Marketing Research: Methodological Foundations. Chicago: South-Western College Publishing, 2001.

14. Cooke, D. Affective, continuance, and normative commitment to the organization: An examination of construct validity. Journal of Vocational Behavior, 49, 3 (December 1997), 252-276.

15. Cronbach, L.J., and Meehl, P.E. Construct validity in psychological tests. Psychological Bulletin, 52, 4 (1955), 281-302.

16. Davenport, T.H., and Prusak, L. Working Knowledge: How Organizations Manage What They Know. Boston: Harvard Business School Press, 2000.

17. Davis, F.D. Technology Acceptance Model for Empirically Testing New End-User Information Systems: Theory and Results. Cambridge, MA: MIT Press, 1986.

18. Davis, F.D. Perceived usefulness, perceived ease of use and user acceptance of information technology. MIS Quarterly, 13, 3 (September 1989), 319-340.

19. Davis, F.D.; Bagozzi, R.P.; and Warshaw, P.R. User acceptance of computer technology-A comparison of two theoretical models. Management Science, 35, 8 (August 1989), 982-1003.

20. DeLone, W.H., and McLean, E.R. The DeLone and McLean model of information systems success: A ten-year update. Journal of Management Information Systems, 19, 4 (Spring 2003), 9-30.

21. Deutsch, M., and Gerard, H.B. A study of normative and informational social influences upon individual judgment. Journal of Abnormal and Social Psychology, 51 (November 1955), 629-636.

22. Dillman, D.A. Mail and Internet Surveys: The Tailored Design Method. New York: Wiley, 2000.

23. Dyer, G., and McDonough, B. The state of knowledge management. Knowledge Management, 4, 5 (2001) (available at www.destinationkm.com/articles/default.asp?ArticleID $=539$ ).

24. Earl, M. Knowledge management strategies: Toward a taxonomy. Journal of Management Information Systems, 18, 1 (Summer 2001), 215-233.

25. Fishbein, M. Attitudes and the prediction of behavior. In M. Fishbein (ed.), Readings in Attitude Theory and Measurement. New York: Wiley, 1967, pp. 477-492.

26. French, J.R.P., and Raven, B. The bases of social power. In D. Cartwright (ed.), Studies in Social Power. Ann Arbor, MI: Institute for Social Research, 1959, pp. 150-167. 
27. Fulk, J.; Steinfield, C.W.; Schmitz, J.; and Power, G. A social information processing model of media use in organizations. Communications Research, 14, 5 (1987), 529-552.

28. Giddens, A. The Constitution of Society: Outline of the Theory of Structuration. Cambridge, Cambridgeshire, UK: Polity Press, 1984.

29. Grover, V., and Davenport, T.H. General perspectives on knowledge management: Fostering a research agenda. Journal of Management Information Systems, 18, 1 (Summer 2001), 5-21.

30. Hartwick, J., and Barki, H. Explaining the role of user participation in information system use. Management Science, 40, 4 (1994), 440-465.

31. Hellman, C.M., and McMillin, W.L. Newcomer socialization and affective commitment. Journal of Social Psychology, 134, 2 (April 1994), 261-262.

32. Hufnagel, E.M., and Conca, C. User response data-The potential for errors and biases. Information Systems Research, 5, 1 (March 1994), 48-73.

33. Kashima, Y., and Kashima, E.S. Individual differences in the prediction of behavioral intentions. Journal of Social Psychology, 128, 6 (1988), 711-720.

34. Kelman, H.C. Compliance, identification, and internalization: Three processes of attitude change? Journal of Conflict Resolution, 2, 1 (1958), 51-60.

35. Kelman, H.C. Processes of opinion change. Public Opinion Quarterly, 25 (Spring 1961), $57-78$.

36. Kelman, H.C. Ethical limits on the use of influence in hierarchical relationships. In J.M. Darley, D.M. Messick, and T.R. Tyler (eds.), Social Influences on Ethical Behavior in Organizations. Mahwah, NJ: Lawrence Erlbaum, 2000, pp. 11-20.

37. Kiesler, C.A., and Kiesler, S.B. Conformity. Reading, MA: Addison-Wesley, 1969.

38. Kirsch, L.J. The management of complex tasks in organizations: Controlling the systems development process. Organization Science, 7, 1 (1996), 1-21.

39. KPMG. Knowledge Management Research Report. KPMG, Amsterdam, 2000 (available at www.insite.cz/data/kpmg_km_report2000.pdf).

40. Lewis, W.; Agarwal, R.; and Sambamurthy, V. Sources of influence on beliefs about information technology use: An empirical study of knowledge workers. MIS Quarterly, 27, 4 (December 2003), 657-678.

41. Malhotra, Y. Role of social influence, self determination, and quality of use in information technology acceptance and utilization: A theoretical framework and empirical field study. Ph.D. dissertation, Katz Graduate School of Business, University of Pittsburgh, 1998.

42. Malhotra, Y., and Galletta, D.F. Role of commitment and motivation in knowledge management systems implementation: Theory, conceptualization, and measurement of antecedents of success. In R.H. Sprague Jr. (ed.), Proceedings of the Thirty-Sixth Annual Hawaii International Conference on Systems Sciences. Los Alamitos, CA: IEEE Computer Society Press, 2003 (available at csdl.computer.org/comp/proceedings/hicss/2003/1874/04/187440115a.pdf).

43. Malhotra, Y., and Galletta, D.F. Building systems that users want to use: Advancing beyond the rhetoric on "Does IT Matter." Communications of the ACM, 47, 12 (December 2004), 88-94.

44. Markus, M.L., and Keil, M. If we build it, they will come: Designing information systems that people want to use. Sloan Management Review, 35, 4 (Summer 1994), 11-25.

45. Melone, N.P. A theoretical assessment of the user satisfaction construct in information systems research. Management Science, 36, 1 (1990), 76-91.

46. Meyer, J.P., and Allen, N. Testing the "side-bet" theory of organizational commitment: Some methodological considerations. Journal of Applied Psychology, 69, 3 (1984), 372 378.

47. Meyer, J.P., and Allen, N.J. Commitment in the Workplace: Theory, Research, and Application. Thousand Oaks, CA: Sage, 1997.

48. Moore, G.C., and Benbasat, I. Development of an instrument to measure the perceptions of adopting an information technology innovation. Information Systems Research, 2, 3 (1991), 192-222.

49. Mowday, R.T.; Porter, L.W.; and Steers, R.M. The measurement of organizational commitment. Journal of Vocational Behavior, 14, 2 (1979), 224-247.

50. Nonaka, I., and Takeuchi, H. The Knowledge-Creating Company: How Japanese Companies Create the Dynamics of Innovation. New York: Oxford University Press, 1995.

51. Nunnally, J.C., and Bernstein, I.H. Psychometric Theory. New York: McGraw-Hill, 1994. 
52. O'Reilly, C.A.I., and Chatman, J.A. Organizational commitment and psychological attachment: The affective compliance, identification, and internalization on pro-social behavior. Journal of Applied Psychology, 71, 3 (1986), 492-499.

53. O'Reilly, C.A.I.; Chatman, J.A.; and Caldwell, D.F. People and organizational culture: A profile comparison approach to assessing person-environment fit. Academy of Management Journal, 34, 3 (1991), 487-516.

54. Orlikowski, W.J. Integrated information environment or matrix of control? The contradictory implications of information technology. Accounting, Management and Information Technology, 1, 1 (1991), 9-42.

55. Pfeffer, J. Power in Organizations. Cambridge, MA: Ballinger, 1981.

56. Pfeffer, J. Organizations and Organization Theory. Marshfield, MA: Pitman, 1982.

57. Porter, L.W.; Steers, R.; Mowday, R.T.; and Boulian, P.V. Unit performance, situational factors, and employee attitudes in spatially separated work units. Organizational Behavior and Human Performance, 12, 2 (1974), 87-98.

58. Reichers, A.E. A review and reconceptualization of organizational commitment. Academy of Management Review, 10, 3 (1985), 465-476.

59. Reichers, A.E. Conflict and organizational commitment. Journal of Applied Psychology, 71, 3 (1986), 508-514.

60. Rice, R.E., and Aydin, C. Attitudes toward new organizational technology: Network proximity as a mechanism for social information processing. Administrative Science Quarterly, 36, 2 (1991), 219-244.

61. Rogers, E.M. Diffusion of Innovations. New York: Free Press, 1995.

62. Salancik, G.R., and Pfeffer, J. Social information processing approach to job attitudes and task design. Administrative Science Quarterly, 23, 2 (1978), 224-253.

63. Schultze, U., and Leidner, D.E. Studying knowledge management in information systems research: Discourses and theoretical assumptions. MIS Quarterly, 26, 3 (September 2002), 213-242.

64. Sheldon, M. Investments and involvements as mechanisms producing commitment to the organization. Administrative Science Quarterly, 16, 2 (1971), 143-150.

65. Stein, E.W., and Zwass, V. Actualizing organizational memory with information systems. Information Systems Research, 6, 2 (1995), 85-117.

66. Sussman, M., and Vecchio, R.P. A social influence interpretation of worker motivation. Academy of Management Review, 7, 2 (1982), 177-186.

67. Sutton, C.D., and Harrison, A.W. Validity assessment of compliance, identification, and internalization as dimensions of organizational commitment. Educational and Psychological Measurement, 53, 1 (Spring 1993), 217-223.

68. Thompson, R.L.; Higgins, C.A.; and Howell, J.M. Personal computing: Toward a conceptual model of utilization. MIS Quarterly, 15, 1 (1991), 125-143.

69. Vandenberg, R.J.; Self, R.M.; and Seo, J.H. A critical examination of the internalization, identification, and compliance commitment measures. Journal of Management, 20, 1 (Spring 1994), 123-140.

70. Venkatesh, V., and Davis, F.D. A theoretical extension of the technology acceptance model: Four longitudinal field studies. Management Science, 46, 2 (February 2000), 186-204.

71. Venkatesh, V.; Morris, M.G.; Davis, F.D.; and Davis, G.B. User acceptance of information technology: Toward a unified view. MIS Quarterly, 27, 3 (2003), 425-478.

72. Venkatraman, N., and Grant, J.H. Construct measurement in organizational strategy research: A critique and proposal. Academy of Management Review, 11, 1 (January 1986), 71-87.

73. Verton, D. Insiders slam Navy intranet. Computerworld (May 27, 2002), 1, 16.

74. Warshaw, P.R. A new model for predicting behavioral intentions: An alternative to Fishbein. Journal of Marketing Research, 17, 2 (1980), 153-172.

75. Weiner, Y., and Vardi, Y. Relationships between job, organization, and career commitments and work outcomes. Organizational Behavior and Human Performance, 26, 1 (1980), 81-96.

76. Wenger, E.; McDermott, R.A.; and Snyder, W. Cultivating Communities of Practice: A Guide to Managing Knowledge. Boston: Harvard Business School Press, 2002.

77. Zack, M.H. Managing codified knowledge. Sloan Management Review, 40, 4 (1999), $45-58$. 
78. Zmud, R.W., and Boynton, A.C. Survey measures and instruments in MIS: Inventory and appraisal. In K. Kraemer (ed.), The Information Systems Research Challenge: Survey Research Methods. Boston: Harvard Business School Press, 1991, pp. 149-180.

79. Zwass, V. Editorial introduction. Journal of Management Information Systems, 16, 1 (Summer 1999), 3-10. 
Appendix A. Demographics of the Samples

\begin{tabular}{|c|c|c|}
\hline Age & $\begin{array}{c}\text { Initial adoption } \\
\text { sample }(n=577) \\
\text { (percent) }\end{array}$ & $\begin{array}{c}\text { Extended use } \\
\text { sample }(n=171) \\
(\text { percent })\end{array}$ \\
\hline$>45$ & 27.2 & 28 \\
\hline $41-45$ & 17.5 & 16 \\
\hline $36-40$ & 22.7 & 20 \\
\hline 31-35 & 14.7 & 16 \\
\hline $26-30$ & 12.5 & 13 \\
\hline $21-25$ & 4.7 & 6 \\
\hline$<21$ & 0.7 & 0 \\
\hline $\begin{array}{l}\text { Highest } \\
\text { education }\end{array}$ & $\begin{array}{l}\text { Initial adoption } \\
\text { sample }(n=583) \\
\quad(\text { percent })\end{array}$ & $\begin{array}{c}\text { Extended use } \\
\text { sample }(n=176) \\
\text { (percent) }\end{array}$ \\
\hline Graduate degree & 22.0 & 21 \\
\hline Bachelor's degree & 38.1 & 44 \\
\hline Associate degree & 18.5 & 15 \\
\hline High school & 21.4 & 19 \\
\hline $\begin{array}{l}\text { Job } \\
\text { category }\end{array}$ & $\begin{array}{l}\text { Initial adoption } \\
\text { sample }(n=581) \\
\quad(\text { percent })\end{array}$ & $\begin{array}{c}\text { Extended use } \\
\text { sample }(n=176) \\
(\text { percent })\end{array}$ \\
\hline Administrative & 26.2 & 24 \\
\hline IS & 9.5 & 11 \\
\hline Management & 16.0 & 17 \\
\hline Medical & 23.9 & 20 \\
\hline Other & 24.4 & 28 \\
\hline $\begin{array}{l}\text { Job } \\
\text { designation }\end{array}$ & $\begin{array}{c}\text { Initial adoption } \\
\text { sample }(n=587) \\
\quad(\text { percent })\end{array}$ & $\begin{array}{c}\text { Extended use } \\
\text { sample }(n=171) \\
(\text { percent })\end{array}$ \\
\hline Assistant & 9.9 & 13 \\
\hline Clerical & 11.1 & 11 \\
\hline Management & 11.1 & 10 \\
\hline Nursing & 10.4 & 10 \\
\hline Physician & 2.0 & 1 \\
\hline Professional & 19.6 & 20 \\
\hline Secretary & 17.4 & 17 \\
\hline Other & 18.6 & 18 \\
\hline
\end{tabular}




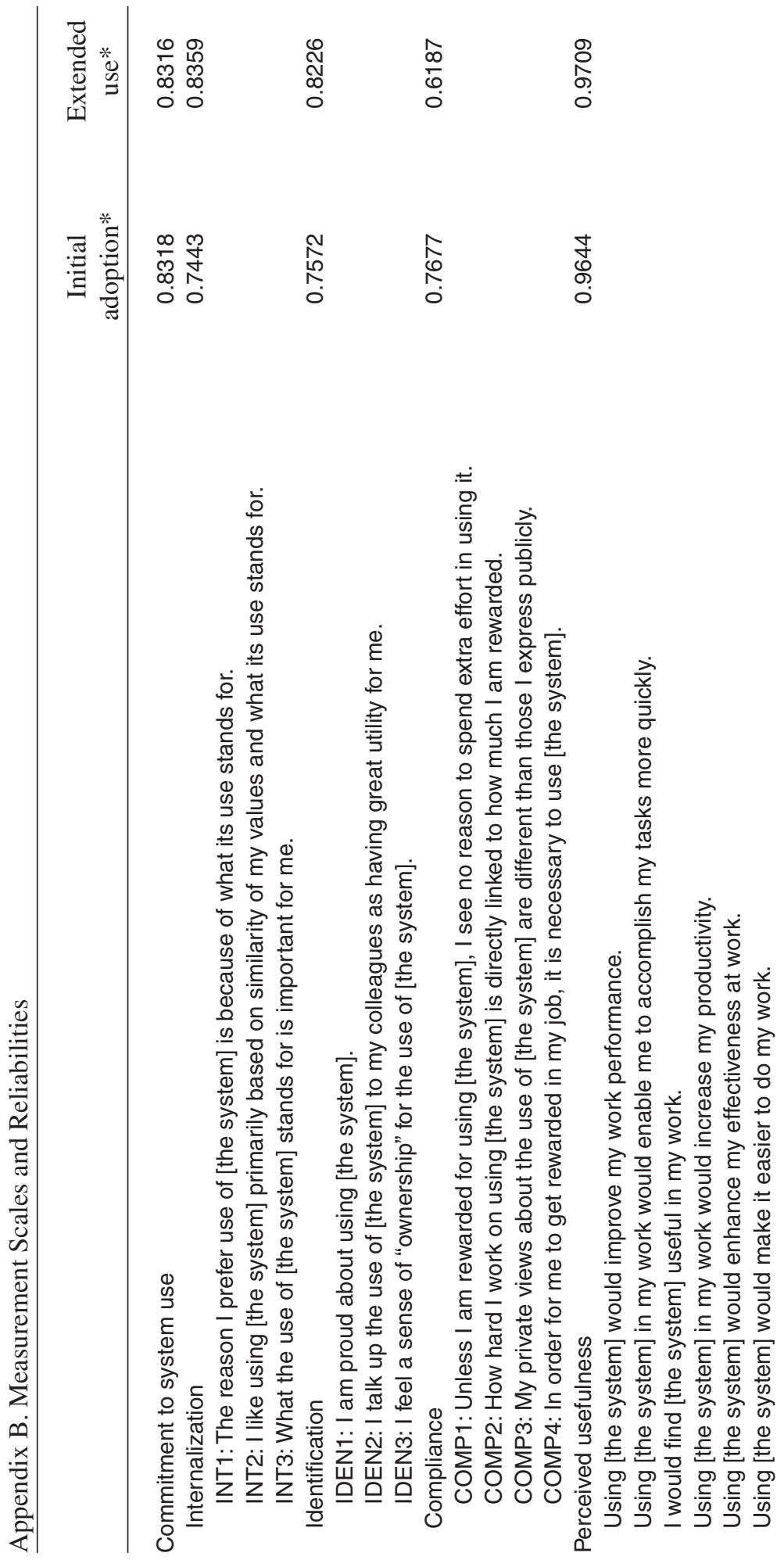


8

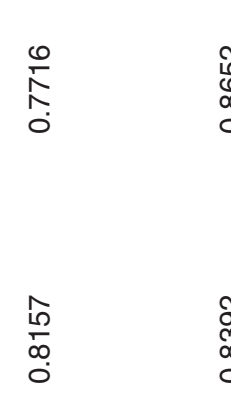

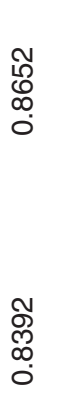

ปั

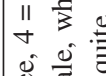

윰

氙

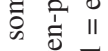

II D

ญ ฮ

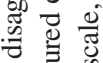

त्ञ

苟

II

i

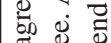

: क्षे

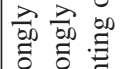

苦

II II

능 공

ह

卷

㐘

党递

.

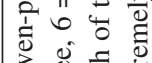

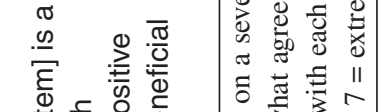

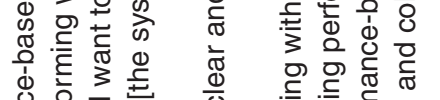

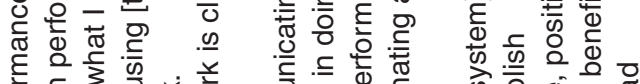

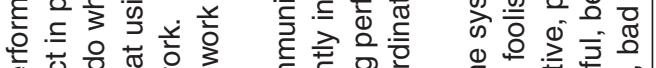

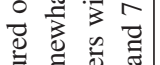

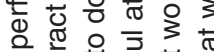

힌

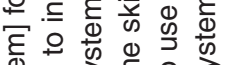

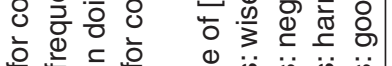

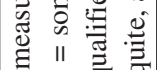

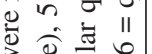

क के हे है के

की

के

की

है은 은 은 은 焉

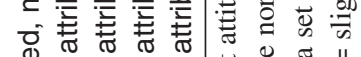

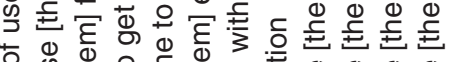

○

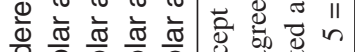

के

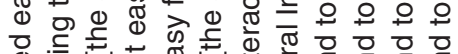

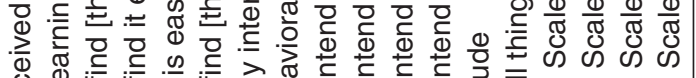

क人 0

x.

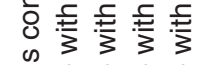

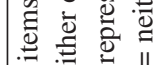

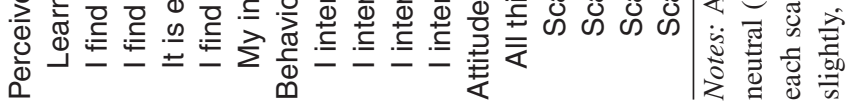

